\begin{tabular}{l|l} 
Jurnal Eksplorasi Akuntansi & $\begin{array}{l}\text { ISSN : 2656-3649 (Online) } \\
\text { holttp://jea.ppj.unp.ac.id/index.php/jea/issue/view/18 }\end{array}$
\end{tabular}

\title{
PENGARUH SIFAT MACHIAVELLIAN DAN POWER DISTANCE TERHADAP KEPUTUSAN WHISTLEBLOWING
}

\author{
Hesti Eka Pratiwi ${ }^{1}$, Sany Dwita ${ }^{2}$ \\ ${ }^{1}$ Alumni Jurusan Akuntansi Fakultas Ekonomi, Universitas Negeri Padang \\ ${ }^{2}$ Jurusan Akuntansi Fakultas Ekonomi, niversitas Negeri Padang \\ *Korespondensi: hestiekap70@gmail.com
}

\begin{abstract}
A number of factors affects the auditors to report unethical behavior in their organizaton. Given the importance of the Machiavellian construct on informing a wide range of ethics research, we focus on gaining a better understanding of Machiavellian within the whistleblower context. We examine the effect of Maciavellian on whisleblowing, focusing on the underlying mechanism through which Machiavelian affects the decision of whistleblowing. Further, because higher Machiavellian are expected to be less likely to report wrongdoing, we examine the ability of an low power distance to increase whistleblowing decision. As Hoftsede research of Indonesian culture, Indonesia has high score (78) on power distance dimention. This research uses experimental method to 67 students of Undergraduate of Accounting in UNP. By using two-case scenarios, partispants were asked to answer the possibility to whistleblow the unethical behavior that occurred in the organization which was done by their manager or peer. The results of this research indicate that the auditors with high Machiavellian has no negative impact for whistleblowing decision. We also find that low power distance has positif impact for whistleblowing decision. Taken together, these findings contribute to the exising literature on accounting ethics.
\end{abstract}

Keywords: machiavellian, power distance, whistleblowing

How to cite (APA $6^{\text {th }}$ style):

Hesti, E. P. \& Dwita, S. (2020). Pengaruh Sifat Machiavellian dan Power Distance terhadap Keputusan Whistleblowing. Jurnal Eksplorasi Akuntansi. 2(1), Seri B, 2185-2199.

\section{PENDAHULUAN}

Anomali moral organisasi semakin banyak bermunculan dalam aliran tanpa akhir. Kejahatan dan perilaku tidak etis dalam organisasi, seperti fraud, korupsi dan kekerasan seksual semakin menjadi fenomena global (Puni dan Anlesinya, 2017). Menelisik beberapa skandal akuntansi di dunia, pada tahun 2014 lalu, tercatat lima skandal akuntansi besar. Tesco di Inggris, Olympus Corporation di Jepang, Penn West Petroleum di AS, Mobily di Arab Saudi, dan Vatican Bank di Italia. Di tahun-tahun sebelumnya, ledakan kasus-kasus akuntansi sering membuat dunia terperangah seperti skandal perusahaan berskala besar (seperti Enron, Tyco, dan 
WorldCom) memiliki dampak buruk bagi investor, karyawan, kreditor dan pemegang kepentingan lainnya (Dalton dan Radtke, 2013).

Di Indonesia sendiri, salah satu skandal besar terjadi pada PT Garuda Indonesia Tbk. Pada tahun 2018, Chairal Tanjung dan Dony Oskaria yang merupakan komisaris PT Garuda Indonesia menganggap laporan keuangan tahun 2018 tidak sesuai dengan Pernyataan Standar Akuntansi Keuangan (PSAK) (Kumparan, 2019). Sehari setelah kabar tersebut beredar, saham perusahaan dengan kode GIAA merosot tajam 4,4\% pada penutupan perdagangan sesi pertama, Kamis (25/4) (Hesti, 2019). Hal tersebut berdampak pada investor, terutama investor kecil karena menderita kerugian yang cukup besar.

Berbagai kasus yang terjadi pada sejumlah perusahaan tersebut terjadi karena adanya pengabaian etika. Kode etik yang ada sering kali dilanggar oleh akuntan, baik pemula sampai profesional sekalipun. Etika profesi akuntan yang dimaksud yaitu tanggung Jawab profesi, kepentingan publik, integritas, obyektivitas, kompetensi dan kehati-hatian profesional, kerahasiaan, perilaku profesional, dan standar teknis. Beberapa cendikiawan (Henle dkk., 2005; McGurn, 1988 dalam Puni dan Anlesinya, 2017) memperkirakan bahwa 75\% orang dalam organisasi terlibat dalam setidaknya satu dari pelanggaran seperti: pencurian, cyber-attack, perusakan properti, penyalahgunaan dana atau sumberdaya, kekerasan seksual dan tanpa kehadiran kerja. Hal ini menunjukkan bahwa budaya perusahaan, politik dan praktik yang telah lama terbentuk mungkin tidak cukup untuk memberikan perlindungan ataupun pencegahan dari peristiwa buruk yang diakibatkan oleh individu dan kelompok dalam perusahaan.

Fenomena whistleblowing memainkan peranan yang sangat penting untuk mengubah kondisi masyarakat menjadi lebih baik. Whistleblowing adalah salah satu langkah penting dalam sebuah perusahaan untuk menunjukkan dukungan mereka terhadap perilaku etis dan mendorong budaya perusahaan yang jujur dan bertanggung Jawab. Memahami faktor-faktor yang dapat mempengaruhi niat pegawai untuk menjadi whistleblower penting dilakukan agar organisasi dapat merancang kebijakan dan sistem whistleblowing yang paling efektif (Setyawati, 2015). Penelitian whistleblowing sebagian besar difokuskan pada tiga faktor yang mempengaruhi pelaporan : (a) faktor individu, seperti demografi, gender, kepribadian, usia, jenis kelamin, pengembangan moral (Chiu, 2003; Ekmen dkk., 2014); (b) faktor situasional, seperti intensitas moral, keseriusan kesalahan, tingkat ambiguisitas kesalahan, posisi whistleblower yang relatif rendah dari pelaku kesalahan (Keenan, 2000;Darjoko dan Nahartyo, 2017; Priyastiwi dan Halim, 2017) dan (c) faktor organisasi, seperti kebijakan pengungkapan internal, kode etik, sistem kompensasi, serta budaya dan iklim organisasi (Puni dan Anlesinya, 2017; Taylor dan Curtis, 2013; Wong-On-Wing dan Lui, 2013). Pemahaman tentang proses menjadi rumit karena kompleksitas variabel dan interaksi diantara variabel-variabel tersebut (Sims dan Keenan, 1998).

Penelitian selanjutnya memerlukan identifikasi mengenai interaksi dari faktor-faktor tersebut seperti interaksi antara faktor individu dengan faktor organisasi (Dalton dan Radtke, 2013) agar terbentuk sistem whistleblowing yang efektif. Taylor dan Curtis (2013) mengatakan penelitian selanjutnya sebaiknya meneliti lebih lanjut bagaimana karakter pribadi dapat mempengaruhi respon organisasi dalam mempengaruhi kecenderungan whistleblowing. Salah satu faktor yang diduga mempunyai implikasi yang signifikan terhadap whistleblowing adalah sifat machiavellian pada individu. Machiavellian dapat dijelaskan sebagai strategi dalam perilaku sosial yang melibatkan perbuatan memanipulasi orang lain untuk kepentingan pribadi yang sering kali berlawanan dengan kepentingan orang lain (Tang dkk., 2007).

Individu dengan sifat machiavellian lebih tinggi cenderung membuat keputusan etis berdasarkan pada kepentingan pribadi dan menggunakan desepsi dan manipulasi untuk mencapai 
tujuan mereka (Dalton, 2012). Hasil penelitian Murphy (2012) mengatakan bahwa individu machiavellian tidak hanya lebih cenderung menyalahgunakan kesempatan dan motif, tetapi mereka juga menanggung beban emosional yang jauh lebih kecil dari kesalahan pelaporan.

Sebuah organisasi tentu mempunyai budaya organisasi tertentu yang telah mengakar sehingga mempengaruhi nilai dan sikap individu di dalamnya. Budaya dapat mempengaruhi perilaku seseorang (Puni dan Anlesinya, 2017). Vedera dkk., (2009) dalam Priyastiwi dan Abdul Halim (2017) menyatakan whistleblowing merupakan proses kompleks, oleh karena itu karakteristik organisasi dapat membantu memahami praktik yang tidak etis untuk dilaporkan. Sejumlah penelitian lintas budaya dalam akuntansi mengacu pada dimensi nilai Hofstede $(1980,1997,2001)$ dalam Wong-On-Wing dan Lui (2013). Berdasarkan model Hofstede (2011), budaya nasional dibagi menjadi enam dimensi yaitu ; power distance, individualism, masulinity, uncertainity avoidance, long term orientatiton, dan indulgence.

Power distance diduga menjadi faktor penting yang mempengaruhi whistleblowing dalam penelitian ini karena tingkat power distance di Indoensia dikatakan tinggi dengan skor 78 (Hofstede Insights, 2019). Power distance didefinisikan sebagai sejauh mana anggota lembaga dan organisasi yang kurang kuat dalam suatu negara mengharapkan dan menerima bahwa kekuasaan didistribusikan secara tidak merata (Hofstede, 2005). Dimensi ini mengungkapkan sejauh mana anggota masyarakat yang bukan pemangku kepentingan (less powerful) menerima dan memperkirakan bahwa kekuasaan didistribusikan secara tidak merata (Aditya, 2017). Masalah mendasar di sini adalah bagaimana masyarakat menangani ketidaksetaraan di antara mereka. Budaya power distance tinggi meningkatkan persepsi konsekuensi negatif terhadap tindakan whistleblowing, seiring whistleblower dipandang sebagai pengkhianat dari pada sebagai seorang pahlawan (Puni dan Anlesinya, 2017).

Dalton dan Radtke (2013) menguji pengaruh sifat machiavellian dan lingkungan etika terhadap whistleblowing, yang dapat ditarik kesimpulan yaitu sifat machiavellian berpengaruh negatif terhadap whistleblowing. Sejalan dengan penelitian Asiye (2015) dan Nugraha (2017) menemukan bahwa sifat Machiavellian berpengaruh terhadap niat melakukan whistleblowing. Penelitian terdahulu oleh Taylor dan Curtis (2013) menguji variabel respon organisasi dan power distance terhadap whistleblowing pada kantor audit, mereka menemukan bahwa ada interaksi antara power distance dan respon organisasi dalam keputusan whistleblowing, lebih lanjut, ditemukan bahwa auditor lebih berniat melaporkan rekan kerja mereka ketika respon organisasi terdahulu lemah dibandingkan ketika respon organisasi terdahulu kuat. Puni dan Anlesinya (2017) dalam penelitiannya yang menguji hubungan antara budaya power distance dan kecenderungan niat whistleblowing di wilayah Africa menemukan bahwa budaya power distance tinggi membentuk "culture of silence", yang mana secara perlahan menyediakan lahan subur bagi kejahatan korporasi dan tingkah laku tidak etis.

Wong-OnWing dan Lui (2013) melakukan studi lintas budaya pada akuntansi dengan menguji kelayakan menggunakan teori implisit sebagai alternatif pendekatan nilai dimensi untuk mempelajari perbedaan budaya dalam konteks penilaian moralitas. Mereka menduga bahwa variabel budaya seperti individualistis, power distance, komunitarianisme, wajah, dan lain-lain, dapat dipandang sebagai manifestasi spesifik dari teori implisit budaya tentang kausalitas. Tujuan penelitian ini adalah untuk menguji secara empiris apakah sifat machiavellian berpengaruh negatif terhadap whistleblowing, menguji secara empiris apakah power distance lemah akan meningkatkan keputusan whistleblowing dibandingkan dengan power distance tinggi dan menguji bagaimana perbedaan tingkat pengungkapan sifat machiavellian tinggi dan rendah terhadap whistleblowing dalam power distance yang lemah. 
Penelitian ini diharapkan dapat berkontribusi untuk pengembangan teori mengenai whistleblowing dengan menjelaskan sifat machiavellian dan power disance yang diduga dapat mempengaruhi keputusan whistleblowing yaitu implementasi dari theory of planned behaviour. Lebih dalam lagi, penelitian ini diharapkan juga memberikan kontribusi dalam menciptakan budaya organisasi yang efektif dalam pengungkapan kecurangan di dalam organisasi dengan teori keadilan sebagai penjelas. Berdasarkan uraian tersebut, maka peneliti memberi judul penelitian ini sebagai "Pengaruh Sifat Machiavellian dan Power Distance terhadap Keputusan Whistleblowing".

\section{REVIU LITERATUR DAN HIPOTESIS \\ Theory of Planned Behavior}

Theory of planned behavior (TPB) merupakan teori yang dapat menjelaskan faktor-faktor yang mempengaruhi individu dalam berperilaku (Ajzen, 1991). Sejauh ini, teori yang paling sering diterapkan pada penelitian dengan keterkaitan antara sikap, niat, dan perilaku adalah theory of planned behavior. Menurut Mahyarni (2013), alat yang dapat digunakan untuk memprediksi perilaku individu ketika individu tersebut tidak memiliki kontrol kemauan sendiri secara penuh adalah theory of planned behavior. The Theory of planned behavior secara khusus cocok untuk menjelaskan niat pelapor dalam hal ini auditor, karena whistleblowing adalah tindakan yang dilakukan berdasarkan pada proses psikologis yang sangat kompleks (Gundlach dkk., 2003 dalam Park dan Blenkinsopp, 2009). Niat yang kemudian akan mempengaruhi perilaku seorang auditor dalam pengambilan keputusan.

Ofstad (1961) dalam Blenkinsp dan Edwards (2008) mengatakan bahwa seseorang telah membuat keputusan berarti mereka telah melakukan satu dari tiga hal, yaitu: (1) memulai serangkaian perilaku reaksi yang mendukung sesuatu; (2) memutuskan untuk melakukan tindakan tertentu, yang tidak diragukan lagi harus dia lakukan; atau (3) membuat keputusan tentang apa yang harus dilakukan seseorang dalam situasi tertentu setelah mempertimbangkan beberapa tindakan alternatif. Randall dan Gibson (1991) dalam Park dan Blenkinsopp (2009) menerapkan TPB untuk memprediksi pengambilan keputusan etis pada profesi medis dan melaporkan bahwa teorinya berhasil menjelaskan maksud untuk melaporkan kesalahan.

\section{Teori Keadilan}

Teori keadilan pertama kali dikemukakan oleh John Rawls. Keadilan (justice) adalah pikiran yang muncul ketika seseorang menerima sesuatu yang mereka dan orang-orang di sekitarnya berhak mendapatkannya (Cohen dalam Pinder, 1998 dalam Runing, 2011). Sesuatu yang dapat diterima ini dapat berupa manfaat atau yang menyusahkan atau juga outcome yang sifatnya non-moneter seperti status dan tanggungJawab. Seseorang akan peduli tidak hanya pada apa yang akan mereka terima tetapi juga peduli pada apa yang orang lain terima.

Teori keadilan menyatakan bahwa individu mendefinisikan keadilan tidak hanya menurut outcome yang diterima tetapi juga menurut prosedur yang mereka digunakan untuk menentukan outcome seseorang, hal ini disebut dengan keadilan prosedural (Levental et al. dalam Skarlicki \& Folger, 1997 dalam Runing, 2011). Hal ini mengarah pada pengertian bahwa keadilan dapat dikategorikan menjadi keadilan yang berfokus pada isi (keadilan distributif) dan keadilan yang berfokus pada proses (keadilan prosedural) (Greenberg, 1990 dalam Runing, 2011).

Power distance adalah gambaran distribusi kekuasaan pada sebuah masyarakat. Teori keadilan mampu menghubungkan power distance dengan keputusan whistleblowing melalui keadilan yang berfokus pada isi maupun pada proses. Perbedaan dalam power distance 
(tinggi/rendah) akan mempengaruhi pentingnya keadilan seseorang dalam mengevaluasi atasan. Karyawan memakai persepsi mereka tentang keadilan organisasi dalam memutuskan apakah akan berperilaku kewarganegaraan dengan ekstra-peran, seperti whistleblowing. Ketika karyawan mempercayai organisasi memperlakukan orang secara adil, mereka umumnya lebih bersedia untuk terlibat dalam kegiatan untuk membantu organisasi mengidentifikasi masalah yang dapat mempengaruhi pencapaian tujuan (Rupp dan Bell 2010 dalam Taylor dan Curtis, 2013). Power distance lemah dapat diartikan sebagai keadilan yang terdistribusi secara merata yang mana diduga dapat mendorong karyawan untuk mengungkapkan pelanggaran dalam perusahaan.

\section{Whistleblowing}

Whistleblowing didefinisikan sebagai perilaku yang ditandai dengan niat serta tindakan ketika karyawan dihadapkan dengan kesalahan dan atau kecurangan dalam organisasi (Bjorkelo dkk., 2010 dalam Erkmen dkk., 2012). Seseorang yang melakukan tindakan whistleblowing disebut dengan whistleblower. Whistleblower sering digunakan untuk merujuk pada seseorang yang berusaha mengungkap kesalahan atau kecurangan yang terjadi dalam organisasi.

Dalam beberapa tahun terakhir, whistleblowing telah dikaitkan dengan praktik audit dan akuntansi. Praktik akuntansi dan peran auditor telah banyak terlibat dalam banyak skandal perusahaan. Beberapa penelitian telah berusaha menjelaskan faktor-faktor yang berkontribusi mengapa akuntan dan auditor memilih atau tidak memilih untuk menjadi whistleblower, termasuk faktor seperti faktor demografi, sikap, kesalahan pelaporan, machiavellian, locus of control, tingkat penalaran moral, retaliation dan efek budaya (Dalton dan Radtke, 2012; Murphy, 2012; Park dan Blenkinsp, 2008; Taylor dan Curtis, 2013 dan Wong-On-Wing dan Lui, 2013).

Taylor dan Curtis (2013) menguji respon organisasi dan power distance terhadap kemungkinan senior auditor untuk melaporkan perilaku tidak etis kolega mereka. Hasil penelitian tersebut mengatakan senior auditor lebih memilih untuk melaporkan kesalahan kolega mereka daripada atasan mereka. Sejalan dengan penelitian tersebut, Erkmen dkk. (2012) melakukan studi empiris tentang perilaku whistleblowing dalam konteks akuntansi. Hasil penelitian tersebut mengatakan bahwa profesional akuntan lebih memilih untuk menjadi whistleblower dalam keadaan tertentu.

Pengaduan dari whistleblower terbukti lebih efektif dari metode lainnya seperti audit intenal dan audit eksternal dalam mengungkap kesalahan dan kecurangan dalam organisasi atau perusahaan (Bagustianto dan Nurkholis, 2015 dalam Suzilla, 2018). Ini dapat dilihat pada kasus besar seperti Enron dan WorldCom, dimana whistleblower lah yang mengungkap skandal kecurangan. Whistleblowing akan terus menjadi penting untuk diteliti karena kecurangan atau tindakan tidak etis selalu terjadi dalam bermacam bentuk. Lebih lanjut lagi, penelitian terhadap whistleblowing penting dilakukan untuk menciptakan sistem yang efektif agar whistleblower muncul sebagai solusi efektik dalam mengentaskan skandal perusahaan.

\section{Sifat Machiavellian}

Kepribadian machiavellian pertama kalli diperkenalkan ada abad ke-16 oleh Niccolo Machiavelli. Niccolo Machiavelli menulis "The Prince" untuk mengambil hati penguasa baru. Penulis "The Prince" menyarankan orang lain tentang bagaimana cara mendapatkan dan mempertahankan kekuasaan yang didasarkan pada kebijaksanaan dan tanpa kebajikan tradisional dalam kepercayaan, kehormatan dan kesopanan (Tang dkk., 2007). 
Machiavellian telah dipelajari dalam sejumlah besar konteks, termasuk akuntansi (Dalton dan Radtke, 2012; Murphy, 2012. Vitel, 1991 dan Garnitz, 2003 dalam Dalton dan Radtke, 2012) mendeskripsikan kepribadian machiavellian sebagai pribadi yang menerima perilaku tidak etis seperti praktek pencurian dan keuangan. Machiavellian adalah prediktor yang dapat diandalkan untuk perilaku yang tidak etis, namun juga mencakup sinisme dan keyakinan yang luas bahwa "akhir membenarkan cara" (Jones dan Paulhus, 2009 dalam Suzilla, 2018).

Karakteristik penting lainnya dari machiavellian tinggi adalah mereka cenderung membuat keputusan etis berdasarkan kepentingan pribadi (Dalton dan Radtke, 2012). Machiavellian tinggi tidak hanya cenderung menyalahgunakan kesempatan, namun mereka juga menanggung emosional yang jauh lebih kecil dari kesalahan pelaporan (Murphy, 2012). Secara umum, individu yang tinggi dalam machiavellian lebih cenderung mengabaikan norma etika ketika berhadapan dengan masalah moral (Dalton dan Radtke, 2012). Misalnya, machiavellian tinggi relatif terhadap machiavellian rendah, lebih cenderung untuk terlibat dalam perilaku kerja kontra produktif (Dahling dkk., 2009), untuk menampilkan perilaku umum yang tidak etis (Tang dan Liu, 2012). Penting sekali mengetahui bagaimana sikap machiavellian mempengaruhi akuntan dalam memutuskan tindakan apa yang akan dia lakukan setelah mengetahui adanya kesalahan atau tindakan tidak etis dalam perusahaan.

Studi oleh Murphy (2012) yang menguji variabel sikap, machiavellian dan kesalahan pelaporan terhadap whistleblowing, lalu menemukan bahwa akuntan dengan sifat machiavellian yang tinggi lebih cenderung salah melaporkan laporan keuangan dibandingkan dengan mereka yang memiliki sifat machiavellian rendah. Individu dengan sifat machiavellian yang tinggi cenderung pragmatis, mempertahankan jarak emosional dan yakin terhadap hasil lebih penting daripada proses (Rodiyah, 2015). Daton dan Radtke (2012), menguji sifat machiavellian dan lingkungan etika terhadap whistleblowing dengan hasil bahwa sifat machiavellian berpengaruh negatif terhadap whistleblowing.

Christie dan Geis (1970) mengembangkan Mach-IV untuk membedakan antara individu yang cenderung setuju dan mereka yang cenderung tidak setuju dengan sikap machiavellian. Mach-IV terdiri atas butir-butir pernyataan yang berhubungan dengan taktik, pandangan sifat manusia dan moralitas abstrak (Tang dkk., 2007).

\section{Power Distance}

Power Distance dapat didefinisikan sebagai sejauh mana anggota dan institusi yang lemah dalam suatu organisasi mengharapkan dan menerima bahwa kekuasaan didistribusikan secara tidak merata (Hofstede, 1980; Hofstede \& Hofstede, 2005). Power distance adalah ukuran relatif jarak dalam posisi di antara dua pihak - dalam kasus ini, antara pengamat dan pelaku kesalahan (Taylor dan Curtis, 2013).

Hierarki didefinisikan dengan baik dan diakui secara publik dalam firma akuntansi tradisional. Power distance dapat memengaruhi keputusan pengamat untuk melaporkan kesalahan yang diamati. Umumnya, rasa hormat atau mungkin takut kepada atasan karena posisi mereka di perusahaan dan pentingnya atasan dalam proses evaluasi dan promosi jabatan. Sebaliknya, rasa hormat kepada rekan seJawat dirasakan kurang, berdasarkan pada kendala dan mekanisme kelembagaan, dan lebih pada sosial psikologi. Meskipun sebagian besar penelitian terkait whistleblowing, asumsi yang dibuat umumnya mengenai power distance diantara pengamat dan pelaku kesalahan (misalnya, Wong-On-Wing dan Lui (2013) mengasumsikan sebagai dua negara dengan power distance rendah/tinggi, Amerika/China; sementara Puni dan Anlesinya (2017) meneliti konteks di mana kondisi power distance rendah, di negara Afrika), 
perbandingan langsung dari perilaku pelaporan terhadap rekan dan atasan dalam perusahaan jarang digunakan. Di bagian ini, peneliti megambil perbedaan pengaruh rekan kerja dan atasan sebagai faktor yang diduga dapat mempengaruhi keputusan individu menjadi whistlebloweryaitu, power distance rendah dan tinggi.

Pada masyarakat dengan power distance tinggi seperti Malaysia dan Slovakia, masyarakat menerima hubungan kekuasaan yang lebih autokratik dan paternalistik. Sementara budaya dengan power distance rendah seperti Austria, Denmark, dan New Zealand, cenderung untuk melihat persamaan di antara orang dan lebih fokus kepada status yang dicapai daripada yang disandang oleh seseorang (Snitker, 2010). Hasil penelitian Taylor dan Curtis (2013) yang menguji variabel respon organisasi dan power distance terhadap whistleblowing pada seniorlevel auditor menemukan bahwa auditor cenderung untuk melaporkan rekan mereka daripada atasan mereka. Hal ini sejalan dengan penelitian Puni dan Anlesinya (2017) yang menguji masyarakat dengan budaya power distance tinggi terhadap kecenderungan whistleblowing di Afrika kemudian menemukan bahwa budaya power distance tinggi meningkatkan persepsi negatif terhadap whistleblowing, bahwa whistleblower dipandang sebagai pengkhianat bukan pahlawan.

Peneliti lain telah mendiskusikan beberapa tipe pengaruh tekanan sosial yaitu compliance pressure, confromity (peer) pressure dan obedience pressure. Sementara ketiganya diduga memiliki potensi untuk mempengaruhi auditor untuk melakukan perilaku yang tidak etis dan pelanggaran, mereka juga dapat diduga dapat mempengaruhi keputusan auditor untuk melaporkan kesalahan. Namun, kepatuhan dan kesesuaian akan muncul untuk mempengaruhi pelaporan secara khusus melalui hubungan antara auditor dan pelanggar (Taylor dan Curtis, 2013). Obedience pressure dapat memengaruhi pelaporan ketika orang yang berbuat salah adalah atasan. Ketika seorang auditor mengamati seorang rekan melakukan tindakan yang tidak etis, conformity pressure dapat mengurangi kemungkinan whistleblower.

\section{Hipotesis}

Berdasarkan kerangka pemikiran penelitian dan teori yang ada maka peneliti menduga bahwa: $\mathrm{H}_{1}$ : Sifat machiavellian akan berpengaruh negatif terhadap keputusan whistleblowing $\mathrm{H}_{2}$ : Individu yang berada pada budaya power distance rendah akan menunjukkan keputusan melakukan whistleblowing yang berbeda dengan individu yang berada pada budaya power distance tinggi.

$\mathrm{H}_{3}$ : Pada budaya power distance lemah, sifat machiavellian yang tinggi akan meningkatkan keputusan melakukan whistleblowing dibandingkan dengan sifat machiavellian yang rendah.

\section{Kerangka Konseptual}

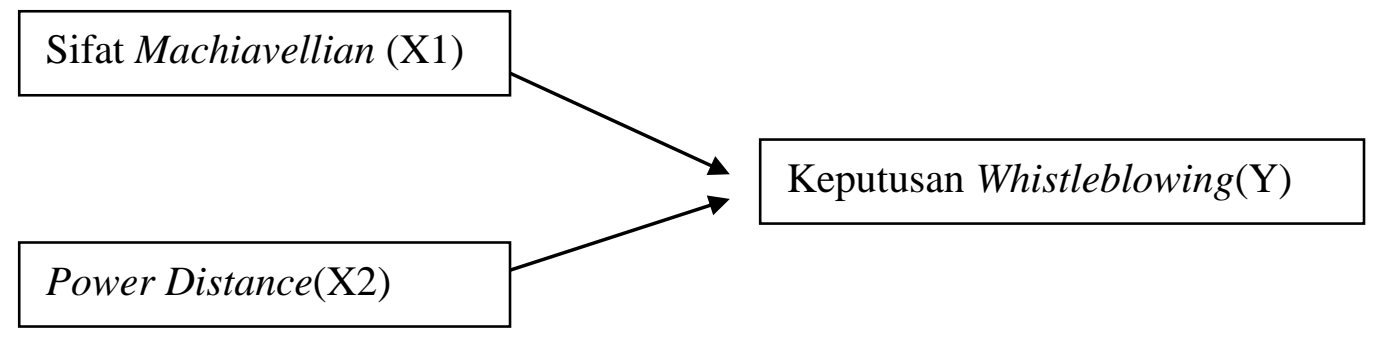

Gambar 1. Model Penelitian 


\section{METODE PENELITIAN \\ Desain Penelitian}

Penelitian ini menggunakan data primer yang dikumpulkan dengan desain eksperimental semu. Eksperimen adalah desain riset untuk menginvestigasi suatu fenomena dengan cara merekayasa keadaan atau kondisi lewat prosedur tertentu dan kemudian mengamati hasil perekayasaan tersebut serta menginterpretasikannya (Nahartyo, 2013). Populasi dalam penelitian ini adalah mahasiswa jurusan Akuntansi di Fakultas Ekonomi Universitas Negeri Padang yang aktif dan terdaftar pada tahun akademik 2018/2019. Jumlah populasi dalam penelitian ini adalah 119 mahasiswa jurusan Akuntansi.

Teknik pengambilan sampel yang digunakan dalam penelitian ini yaitu purposive sampling dengan kriteria; telah mengikuti dan lulus mata kuliah Pengauditan 2 dan Etika Bisnis dan Profesi Akuntan. Asumsi peneliti, bahwa mahasiswa yang telah mengikuti dan lulus mata kuliah Pengauditan 2 telah mengetahui prosedur audit, untuk mata kuliah Etika Bisnis dan Profesi Akuntan diasumsikan bahwa mahasiswa telah mengetahui Kode Etik dan paham akan kasus yang akan disajikan peneliti. Surakhmad (1994) dalam Riduwan (2010) merumuskan penentuan sampel sebagai berikut:

Keterangan :

$$
S=15 \%+\frac{1000-\mathrm{n}}{1000-100} \cdot(50 \%-15 \%)
$$

$S=$ Jumlah sampel yang diambil

$\mathrm{n}=$ Jumlah anggota populasi

Jumlah anggota populasi dalam penelitian ini adalah 119 mahasiswa, maka jumlah minimum sampel dalam penelitian ini adalah:

$$
\begin{gathered}
S=15 \%+\frac{1000-119}{1000-100} \cdot(50 \%-15 \%) \\
S=15 \%+\frac{881}{900} \cdot(35 \%) \\
S=15 \%+0,98(35 \%) \\
S=15 \%+0,343 \\
S=0,493 \\
S=49,3 \%
\end{gathered}
$$

Jumlah minimum sampel yang dapat digunakan dalam penelitian ini $(119 \times 49,3 \%=$ $58,67)$ adalah hasil pembulatan yaitu 59 responden. Agar memudahkan proses analisi data, peneliti menjadikan 70 responden sebagai sampel minimum.

Mahasiswa digunakan sebagai penyulih senior auditor dalam penelitian ini. Terdapat asumsi dalam literatur psikologi bahwa perilaku subjek mahasiswa tidak berbeda dengan perilaku subjek yang berasal dari latar belakang yang berbeda (Nahartyo, 2013). Penelitian Khera dan Benson dalam Nahartyo (2013) mengisyaratkan bahwa mahasiswa akan berperilaku menyerupai pebisnis dalam halnya mereka menguasai tugas eksperimental yang diberikan peneliti. Peneliti juga harus mempertimbangkan kompleksitas penelitian dimana pengalaman atau kepakaran atas suatu bidang dibutuhkan. Penelitian ini berfokus pada bagaimana subjek memproses informasi dan mengambil keputusan secara umum.

Dalam kasus yang peneliti adopsi, subjek yaitu mahasiswa diminta berperan sebagai senior auditor yang menghadapi kasus pelaggaran kode etik oleh manajer/rekan seJawatnya. Peran dalam kasus ini tidak membutuhkan pengalaman atau kepakaran dalam suau bidang. Desain eksperimen yang digunakan dalam penelitian ini adalah desain faktorial $2 \times 2$. Variabel independen terdiri dari sifat machiavellian dan power distance. Variabel terikat adalah keputusan 
whistleblowing. Variabel independen yang dimanipulasi adalah power distance, yaitu dimanipulasi menjadi power distance rendah dan power distance tinggi. Manipulasi pada variabel power distance dilakukan dengan menentukan pelaku kesalahan sebagai rekan/atasan (Taylor dan Curtis, 2013). Variabel yang diukur adalah variabel sifat machiavellian dan whistleblowing.

\section{Tabel 1}

Desain Faktorial $2 \times 2$

\begin{tabular}{ccc}
\hline $\begin{array}{c}\text { Sifat Machiavellian } \\
\text { Power Distance }\end{array}$ & Tinggi & Rendah \\
\hline Rendah & WSB 1 & WSB 2 \\
\hline Tinggi & WSB 3 & WSB4 \\
\hline
\end{tabular}

\section{Instrument Penelitian}

Instrumen penelitian diadopsi dari Alleyne dkk., (2019) untuk variabel whistleblowing, Christie dan Geis (1970) dalam Dalton dan Radtke (2012) untuk variabel sifat machiavellian dan Taylor dan Curtis (2013) untuk variabel power distance. Instrumen pada penelitian ini sudah pernah di uji oleh peneliti terdahulu di Indonesia seperti Nugraha (2017) dan Rodiyah (2015) untuk menguji faktor sifat machiavellian terhadap whistleblowing. Taylor dan Curtis (2013) pernah meneliti variabel power distance terhadap whistleblowing. Di Indonesia, masih sedikit penelitian terkait power distance yang mengadopsi skema (peer/superior) dari Taylor dan Curtis (2013).

Sebelum melakukan penelitian, uji coba dilakukan pada 11 mahasiswa Fakultas Ekonomi Universitas Negeri Padang diluar populasi penelitian dengan rincian; 7 mahasiswa Akuntansi, 2 mahasiswa Manajeman, 1 mahasiswa Pendidikan Ekonomi dan 1 mahasiswa Ilmu Ekonomi. Uji coba dilakukan agar mendapatkan kuesioner yang layak untuk diberikan kepada sampel. Kuesioner dibagikan secara random menjadi dua perlakuan yaitu sebagian mendapat perlakuan power distance rendah dan sisanya mendapat perlakuan power distance tinggi. Skema kasus kemudian dideskripskan sebagai tindakan tidak etis yang dilakukan oleh manager atau rekan seJawat. Skema tindakan tidak etis diambil peneliti karena skandal besar tejadi karena adanya pengabaian hal-hal kecil seperti etika. Kode etik seringkali dilanggar akuntan karena dinilai sepele dan dinilai tidak menguntungkan jika dipatuhi.

Instrumen penelitian ini terdiri dari IV bagian. Bagian I berisi data untuk mendapatkan info demografi partisipan. Bagian II berisi skema kasus whistleblowing. Skema kasus whistleblowing diadopsi dari Alleyne dkk., (2019) yang mengilustrasikan seorang senior auditor yang mengamati pelanggaran kode etik yang dilakukan oleh manager atau rekan seJawat. Pengamat (partisipan) kemudian harus memutuskan apakah akan melaporkan permasalahan tersebut kepada atasan atau tidak.

Bagian III berisi skenario pendek tentang power distance yang diadopsi dari Taylor dan Curtis (2013). Bentuk manipulasi pada variabel power distance adalah power distance rendah dan tinggi. Manipulasi menggunakan teknik simulasi peran, dimana pelaku kesalahan berperan sebagai rekan seJawat atau manager.

Asumsikan Anda adalah senior auditor yang ditugaskan untuk mengaudit PT. ABC. Ini adalah tahun pertama Anda ditugaskan untuk melakukan audit di PT. ABC. Manajer [Rekan seJawat] audit Anda adalah Henri. Manajer [Rekan seJawat] 
Anda, Henri, telah bertugas di PT. ABC untuk mengaudit selama tiga tahun terakhir dan sangat disukai oleh klien.

Memastikan partisipan memahami skema kasus dan manipulasi yang diberikan sudah realistik dan dapat dipahami, maka dilakukan uji manipulasi. Pengecekan manipulasi dilakukan dengan mengajukan pertanyaan : "Apakah kasus ini berhubungan dengan manajer atau rekan seJawat?". Kemudian, partisipan dikatakan lulus uji manipulasi apabila merespon sesuai dengan kasus yang telah diberikan dengan mencentang salah satu pilihan (manajer/rekan seJawat). Apabila Jawaban sesuai dengan kasus yang diberikan, maka subjek dapat dikatakan lulus uji manipulasi.

Bagian IV berisi kuesioner untuk mengukur sifat machiavelllian dengan pengukuran Mach-IV yang terdiri dari 20 item pertanyaan, dimana pertanyaan pada item 1,3,4,6,7,9,12,16,18 dan 19 merupakan item positif dan sisanya 2,5,8,10, 11,13,14,15,17, dan 20 adalah item negatif.

Dalam pelaksanaan pengembangan instrumen, dilakukan beberapa penyesuaian yang diperlukan pada kuesioner. Metode translation-backtranslation digunakan dalam mengadopsi intrumen dari penelitian terdahulu.

\section{Prosedur Penelitian}

Eksperimen ini merupakan quasi eksperimen dengan desain faktorial antarsubjek, dimana subjek diminta untuk menelaah dan memutuskan tindakan berkaitan dengan kasus-kasus whistleblowing. Penelitian ini menggunakan teknik pengumpulan data dengan metode survei dalam bentuk kuesioner yang diberikan secara personal untuk mendapatkan data primer. Eksperimen dimulai dengan memberikan arahan kepada partisipan mengenai tata cara pengisian kuesioner. Kuesioner dibagikan secara random dengan dua perlakuan. Randomisasi dilakukan untuk memastikan bahwa haya variabel indpenden saja yang mempengaruhi variabel dependen ( Kinney, 1986 dalam Dalton, 2012).

Pada kasus dengan perlakuan power distance lemah, partisipan akan menerima kasus dimana rekan sejawat yang melakukan tindakan tidak etis. Pada perlakuan power distance tinggi, partisipan akan menerima kasus dimana manajer yang melakukan tindakan tidak etis. Selanjutnya, partisipan diminta pendapatnya melalui skala likert 7 poin. Berbeda dengan variabel sifat machiavellian, yang dikelompokkan berdasarkan tinggi dan rendah, hanya dapat diketahui setelah tabulasi data dilakukan.

Perlakuan pada kelompok 1 : Diberikan kasus whistleblowing yang sama setiap kelompok, pastisipan dengan sifat machiavelian yang tinggi dan kasus power distance yang rendah. Pada kelompok 2 : Diberikan kasus whistleblowing yang sama setiap kelomok, partisispan dengan sifat machiavelian yang rendah dan kasus power distance yang rendah. Pada kelompk 3 : Diberikan kasus whistleblowing yang sama setiap kelompok, partisispan dengan sifat machiavelian yang tinggi dan kasus power distance yang tinggi. Pada kelompok 4 : Diberikan kasus whistleblowing yang sama setiap kelompok, partisispan dengan sifat machiavelian yang rendah dan kasus power distance yang tinggi.

\section{Pengukuran Variabel}

Tiga variabel diteliti dalam penelitian ini, yaitu : variabel keputusan whistleblowing sebagai variabel dependen; variabel sifat machiavellian sebagai variabel independen dan; 
variabel power distance sebagai variabel independen sekaligus moderating. Sifat machiavellian dan power distance dapat mempengaruhi individu dalam mengambil keputusan.

Variabel keputusan whistleblowing adalah keputusan seseorang untuk mengungkapkan suatu kesalahan atau tindakan tidak etis yang dia ketahui. Variabel ini diukur dengan meminta pendapat partisipan atas keputusan melakukan whistleblowing yang diukur dengan melakukan skala likert 1 sampai 7 dari sangat tidak setuju (STS) sampai sangat setuju (SS). Sebanyak dua pertanyaan diajukan kepada partisipan dalam bentuk orang pertama (dirinya sendiri) dan orang ketiga (orang lain). Hal ini dilakukan karena penelitian sebelumnya menemukan bahwa ada perbedaan tingkat keputusan whistleblowing berdasar perspektif pelapor.

Variabel power distance merupakan variabel yang dimanipulasi. Variabel ini diukur dengan membagi pasrtisipan menjadi dua perlakuan yang dimanipulasi yaitu power distance lemah dan power distance kuat. Skala nominal digunakan dengan skor 1 untuk power distance tinggi dan skor 2 untuk power distance rendah.

Variabel independen sifat machiavellian diproksikan dengan mach-IV menjadi tingggi dan rendah. Mach-IV terdiri dari 20 item pernyataan dengan skala likert 1 sampai 7 dari sangat tidak setuju sampai sangat setuju. Lebih lanjut lagi, nilai dari sifat machiavellian merupakan hasil tabulasi dari 20 item pernyataan ditambah dengan nilai konstana 20, menghasilkan berbagai skor 40-160 dengan teori netral pada 100. Christie dan Geis (1970); Hunt dan Chonko (1984) dalam Dalton (2012), skor lebih dari 100 cenderung mewakili individu dengan sifat machiavellian yang tinggi, sedangkan sifat machiavellian rendah dengan skor dibawah 100 . Namun tidak ada titik cut off mutlak secara definitif yang membedakan rendah dan tingginya tingkat machiavellian individu. Berdasarkan hal tersebut peneliti mengggunakan skor Mach $>90$ yang dikategorikan sebagai sifat machiavellian yang tinggi. Peneliti berpendapat bahwa skor tersebut lebih mendekati objek yang diteliti. Pada tahap lanjut, skor machiavellian yang telah dijumlahkan akan disimbolkan dengan skala nominal dimana sifat machiavellian rendah akan diberi simbol 1 dan sifat machiavellian tinggi disimbolkan dengan skor 2.

\section{Uji Hipotesis}

Uji hipotesis pertama dan kedua dilakukan dengan menggunakan uji one way ANOVA. Kemudian untuk hipotesis ketiga dilakukan uji two way ANOVA.

\section{HASIL PENELITIAN}

\section{Sifat Machiavellian akan Berpengaruh Negatif Terhadap Keputusan whistleblowing.}

Hasil pengujian menunjukkan adanya perbedaan antara individu dengan sifat machiavellilan tinggi dan rendah terhadap keputusan whistleblowing, namun tidak menunjukkan arah sesuai dengan $\mathrm{H}_{1}$ yang diduga peneliti, apakah selalu individu dengan sifat Machiavellian tinggi akan berpengaruh negatif terhadap keputusan whistleblowing.

Sifat Machiavellian diduga akan berengaruh negatif terhadap whistleblowing karena pribadi ini cenderung bertindak berdasarkan keuntungan pribadi, sehingga tidak akan langsung setuju untuk menjadi whistleblower tanpa ada keuntungan pribadi bagi dirinya. Mahasiswa akuntansi sebagai objek yang diteliti mungkin masih menganggap kasus yang diberikan sebagai tes bahwa mereka paham akan mata kuliah yang telah diberikan sehingga tidak semua individu dengan sifat Machiavellian tinggi akan menurunkan keputusan whistleblowing mereka.

Penelitian mengenai sifat Machiavellian terhadap whistleblowing telah dilakuakan oleh beberapa peneliti sebelumnya. Hasil penelitian ini konsisten dengan penelitian Nugraha (2017) 
dan Rodiyah (2015) yang menyatakan adanya pengaruh sifat Machiavellian terhadap keputusan whistleblowing

Individu yang berada pada budaya power distance rendah akan menunjukkan keputusan melakukan whistleblowing yang berbeda dengan individu yang berada pada budaya power distance tinggi.

Hasil dari pengujian hipotesis kedua menunjukkan bahwa individu pada budaya power distance rendah akan menunjukkan keputusan melakukan whistleblowing yang berbeda dibandingkan dengan individu yang berada pada buadaya power distance tinggi. Hasil penelitian sejalan dengan penelitian Taylor dan Curtis (2013), Puni dan Anlesinya (2017) dan Wong-On Wing dan Lui (2013) bahwa budaya power distance mempengaruhi keputusan untuk melakukan whistleblowing. Budaya yang kekuasaannya terdistrbusi secara tidak merata membuat hierarki kekuasaan mengerucut sehingga pada lapisan paling bawah merasa ada tekanan ketika hendak melaporkan atasan.

Pada budaya power distance lemah, sifat Machiavellian yang tinggi akan meningkatkan keputusan melakukan whistleblowing dibandingkan dengan sifat Machiavellian yang rendah.

Hasil pengujian hipotesis didapat nilai $p>0.05$ dengan dugaan Machiavellian tinggi pada power distance rendah dengan Machiavellian rendah pada power distance rendah. Mean rank yang didapat adalah 13.60 untuk sifat Machiavellian tinggi pada power distance rendah dan 19.16 pada sifat Machiavellian rendah pada power distance rendah. Peneliti menduga bahwa tidak terdukungnya hipotesis ketiga karena responden masih dengan pemikiran ideal mengenai whistleblowing yang merupakan tindakan yang benar yang harus dilakukan setiap auditor ketika hal tersebut berkenaan dengan terganggunya independensi.

Tabel 2

Hasil

\begin{tabular}{|c|c|c|c|c|c|c|}
\hline \multicolumn{4}{|c|}{ Uji Parametrik } & \multicolumn{3}{|c|}{ Uji Non-Parametrik } \\
\hline \multicolumn{4}{|c|}{ Uji ANOVA } & \multicolumn{3}{|c|}{ Uji Mann-Whitney } \\
\hline & Mean & $\mathrm{F}$ & Sig & & Mean Rank & Sig \\
\hline \multirow{2}{*}{$\begin{array}{c}\text { Sifat } \\
\text { Machiavellian }\end{array}$} & \multirow{2}{*}{14,411} & \multirow{2}{*}{6,454} & \multirow{2}{*}{0,014} & SM Rendah & 37,99 & \multirow{2}{*}{0,061} \\
\hline & & & & SM Tinggi & 29,08 & \\
\hline \multirow{2}{*}{ Power Distance } & \multirow{2}{*}{435,142} & \multirow{2}{*}{194,881} & \multirow{2}{*}{0,000} & PD Rendah & 16,47 & \multirow{2}{*}{0,000} \\
\hline & & & & PD Tinggi & 49,1 & \\
\hline \multirow{5}{*}{$\mathrm{SM} * \mathrm{PD}$} & \multirow{5}{*}{2,387} & \multirow{5}{*}{1,069} & \multirow{5}{*}{0,305} & Uji Kruskal & Wallis & \\
\hline & & & & Mach rendah_PD rendah & 19,16 & \multirow{4}{*}{0,000} \\
\hline & & & & Mach tinggi_PD rendah & 13,6 & \\
\hline & & & & Mach rendah_PD tinggi & 52,33 & \\
\hline & & & & Mach tinggi_PD tinggi & 44,57 & \\
\hline
\end{tabular}




\section{SIMPULAN, KETERBATASAN, KETERBATASAN \\ Simpulan}

Berdasarkan hasil temuan penelitian dan pengujian hipotesis yang telah dilakukan dapat disimpulkan bahwa individu yang berada pada budaya power distance rendah akan menunjukkan keputusan melakukan whistleblowing yang berbeda dengan individu yang berada pada budaya power distance tinggi.

\section{Keterbatasan}

Penelitian ini memiliki keterbatasan yaitu sebagian kecil responden dalam penelitian ini kurang berpartisipasi penuh dalam prosedur yang telah peneliti jelaskan, sehingga perlakuan atau sugesti yang dirancang peneliti dalam kasus kurang dipahami yang berdampak pada tidak lulus dalam uji manipulasi.

\section{Saran}

Berdasarkan penelitian ini maka bisa diajukan beberapa saran yang dihasilkan dari penelitian ini: (1) Peneliti selanjutnya diharapkan dapat merancang prosedur yang efektif untuk memicu responden dalam mengerjakan kuesioner agar treatment/perlakuan yang diberikan dapat mempengaruhi responden dalam menanggapi skenario yang diberikan. (2) Peneliti selanjutnya juga diharapkan meneliti tentang interaksi ketiga factor whistleblowing yaitu factor individu, situasional dan organisasi, agar menghasilkan informasi yang lebih layak mengenai whistleblowing.

\section{Implikasi}

Penelitian ini memiliki implikasi yang dihasilkan yaitu: (1) Bagi organisasi agar dapat membentuk budaya organisasi yang tidak mencermikan jarak kekuasan yang sangat jauh (sebaiknya kekuasaan didistribusikan secara merata bukan terpusat). (2) Bagi organisasi agar dapat menemukan cara untuk memicu karyawan dengna karakter individu tertentu untuk ikut berpasrtisipasi mewujudkan organisasi yang bebas dari tindak kecurangan melalui tindakan whistleblowing. (3) Bagi akademisi agar dapat menanamkan "etika profesi akuntan" dan memahamkan arti pentingnya whistleblowing bukan hanya untuk kepentingan perusahaan saja namun kepentinga stakeholder atau orang banyak.

\section{DAFTAR PUSTAKA}

Agustinus, Michael., Muslimawati, Nicha. dan Agustinus, Michael. (2019, Juni 28). Fakta-fakta Skandal Laporan Keuangan Garuda. Kumparan. Diakse dari https://kumparan.com/@kumparanbisnis/fakta-fakta-skandal-laporan-keuangan-garuda1rMwNVMNWKZ

Ajzen, I. (1991). The Theory of Planned Behavior. Organizational behavior and human decision processes. 50. 179-211.

Alleyne, Philmore, dkk. (2019). Does group cohesion moderate auditors' whistleblowing intentions?. Journal of International Accounting, Auditing and Taxation. 34, 69-90.

Blenkisopp, John dan Edwards, Marissa S. (2015). Chapter 8 On Not Blowing The Whistle: Quiescent Silence As An Emotion Episode. Emotions, Ethics and Decision-Making. 4, 181-206. 
Bouville, Mathieu. (2007). WhistleBlowing and Morality. Journal of Business Ethics. 2008 (81); $579-585$

Chiu, R.K. (2003). Ethical Judgement and whistleblowing intention : examining the moderating role of locus control. Journal of Business Ethics. 43

Dalton, Derek \& Robin R. Radtke. (2012). The Join Effects of Machiavellianism and Ethical Environment on Whistleblowing. Journalof Business Ethics. 117:153-172.

Ekosetio, Teguh. (2019, Agustus 02). Wistle Blower BUMN dan PLN Akankah Dapat Bertahan Menjadi Lembar Pengaduan. Kompasiana. Diakses dari https://www.kompasiana.com/teguheko/5d42cf480d82303c713bf9a2/wistle-blower-bumndan-pln-akankah-dapat-bertahan-menjadi-lembar-pengaduan?page=all

Ghozali, Imam. (2013). Aplikasi analisis multivariate dengan prgram IBM SPSS 21. Badan Penerbit Universias Diponegoro : Semarang.

Hofstede Insight. (2019). Country Comparison. Diakses 01 November 2019, dari https://www.hofstede-insights.com/country-comparison/indonesia/

https://www.dictio.id/t/apa-yang-dimaksud-dengan-power-distance/4911

Integrity Indonesia. (2017). Skandal Keuangan Perusahaan Toshiba. Diakses 17 Oktober 2019, dari https://www.integrityindonesia.com/id/blog/2017/09/14/skandal-keuanganperusahaan-toshiba/

Kaplan, S. E., and S. M. Whitecotton. 2001. An examination of auditors' reporting intentions when another auditor is offered client employment. Auditing: A Journal of Practice \& Theory 20 (1): 45-63.

Katadata.co.id. (2019). Dituding Palsukan Laporan Keuangan Saham GE Anjlok 11\%. Diakses 17 Oktober 2019, dalam https://katadata.co.id/berita/2019/08/16/dituding-palsukanlaporan-keuangan-saham-ge-anjlok-11

Keenan. (2000). Blowing the wistle on less serious form of fraud : a study of executives and managers. Employee Responsibilities and Rights Journal. 12(4), 199-217. Doi : 110.1023/A:1022820210577.

Mahyarni. (2013). Theory of reasoned action dan theory of planned behavior (sebuah kajian historis tentang perilaku). E-journal. $4: 1$.

Murphy, Pamela R. (2012). Attitude, Machiavellianism and the Ratinalization of misreporting. Accounting Organizations and Society. $37: 242-259$.

Muthaher, Osmad. (2019, 27 Juni). Penyebab dan Solusi Penyimpangan Etika Akuntansi Manajemen.

Kompasiana. https://www.kompasiana.com/ulinnuha14/5d14cb77097f3645237151a3/penyebab-dansolusi-penyimpangan-etika-akuntansi-manajemen?page=all

Nahartyo. Ertambang. (2013). Desain dan Implementasi Riset Eksperimen (Edisi kedua). Yogyakarta : UPP STIM YKPN.

Ohyver, Margaretha. (2018). Uji Nonparametrik. Diakses tanggal 25 Januari 2020, dari https;//socs.binus.ac.id/2018/12/08/uji-nonparametrik/

Ghozali, Imam. (2018). Aplikasi Analisis Multivariate dengan Program IBM SPSS 25 (Edisi 9). Semarang : Badan Penerbit Universitas Diponegoro.

Oktarianisa, Sefti. (2019, Agustus 16). General Electric Diduga Manipulasi Laporan Keuangan US\$ 38 M. CNBC Indonesia. https://www.cnbcindonesia.com/news/20190816121319-492493/general-electric-diduga-manipulasi-laporan-keuangan-us--38-m

Park, Heungsik dan Blenkinsopp, John. (2009). Whistleblowing as Planned Behavior -A Survey of South Korean Police Officers. Journal of Business Ethics. 85, 545-556. 
Puni, Albert dan Anlesinya, Alex. (2017). Whistleblowing Propensity in Power Distance Societies. Journal of Global Responsibility. 29.

Runing, Hunik. (2011). Jarak Kekuasaan sebagai Pemoderasi Pengaruh Keadilan Organisasional Terhadap Komitmen Karyawan pada Supervisor. Jurnal Manajemen Teori dan Terapan |. 4(3).

Semendawai dkk. (2011). Memahami Whistleblower. Lembaga Perlindungan Saksi dan Korban (LPSK) Jakarta.

Setyawati, Intan dkk. (2015). Faktor-faktor yang mempengaruhi niat untuk melakukan whisleblowing internal (the factors influencing internal whistleblowing intentions). Jurnal Ekonomi dan Bisnis. 17(2).

Taylor, E. Z., \& Curtis, M. B. (2013). Whistleblowing in audit firms : organizational response and power distance. Behavioral Research in Accounting, 25(2), 21-43. Doi: 10.2308/bria50415.

Wong-On-Wing, Bernard dan Lui, Gladie. (2013). Beyond Cultural Values: An Implicit Thery Approachh to Cross-Cultural Researc in Accounting Ehics. American Accounting Association. 25(1), 15-3 